\title{
Effects of COVID-19 on Women and Children in Kenya
}

\author{
Dr. Catherine Mwihia \\ University of Kabianga
}

\begin{abstract}
Six months into the COVID-19 crisis, thousands of news stories have been published warning of the increased risks of violence against women and children. School closures, social distancing and confinement increase the risk of poor nutrition among children, their exposure to domestic violence, increase their anxiety and stress, and reduce access to vital family and care services. Research from previous health, economic, and political crises supports this dynamic, predicting increases in multiple risk factors for diverse forms of violence. Yet most press coverage relies on month-to-month statistics from highly volatile single sources from high-income countries like helplines, hospitalizations, and police records. This paper review rigorous studies that have analyzed how COVID-19 and related policies are impacting rates of violence against women and children and highlight more reliable methods, while acknowledging limitations of underlying data sources. COVID-19 has exposed the vulnerability of many families to deal with economic shocks. Countries have therefore introduced emergency to give families extra cash. Local governments also provide extra support. The COVID-19 crisis will make children vulnerable who were not vulnerable before. In the aftermath of the crisis, health, education and family support services should take on board the lessons learnt on how to best develop resilient and crisis-proof child policies, data and service infrastructures to support families and children. Understanding mechanisms underlying these dynamics are important for crafting policy and program responses to mitigate adverse effects. This paper may be used by researchers, practitioners, and policymakers to help inform further evidence generation and policy action while situating violence against women and children within the broader need for intersectional gender- and feminist-informed pandemic response.
\end{abstract}

Keywords: Pandemics, women, violence, against, children, COVID-19

DOI: $10.7176 / \mathrm{JPCR} / 54-01$

Publication date:July $31^{\text {st }} 2021$

\section{Introduction}

By now, it has been apparent that not only is the COVID-19 pandemic a public health epidemic, it has already contributed to a massive global economic slowdown. Employment losses for men have been much higher than for women in previous recessions, such as the one in 2008. One explanation is that in industries highly impacted by a "standard" slowdown (such as manufacturing and construction), comparatively more men work, while women's employment is concentrated in less cyclical sectors such as health care and education. The current recession, on the other hand, has a huge effect on service occupations with a large share of female jobs, such as restaurants and hospitality. The fact that most countries have agreed to close schools and daycare centers in the aftermath of the pandemic is an even more critical channel for unequal impacts on women and men. More than 1.5 billion children worldwide are out of school right now (UNESCO, 2020). This has raised the demand for childcare significantly. Furthermore, owing to the higher mortality rate for the elderly, grandparent-provided childcare is now prohibited, and given social distancing steps, sharing childcare with neighbors and friends is now very limited. Many families, however have no choice but to watch their children themselves.

Mothers are expected to be more affected than fathers, based on the actual allocation of child care responsibilities of most households. The greatest hit would be single mothers, many of whom are in the United States, and who are already in a disadvantaged economic situation to begin with. Taken together these variables indicate that the COVID-19 pandemic would have a disproportionate detrimental impact on women and their prospects for jobs (China Center for Disease Control 2020). It is possible that the consequences of this shock will outlast the real outbreak.

Staff who are now neglecting employment are returning to practice and are expected to have less stable employment in the future (Jarosch 2015). The implications are limited not only to those who lose jobs, but also to those who are about to enter the labour market for the first time (Altonji, Lisa and Jamin 2016). Despite this pessimistic outlook, we still agree that certain reforms that have the potential to minimize gender disparity in the labor market in the long term could arise from the COVID-19 crisis. First of all, we remember that much of the gender imbalance in the labour market today is due to an unfair division of labor in the household.

It is changing the day-to-day lives of children as the COVID 19 epidemic unfolds across the world. About every aspect of the children's planet is influenced by the pandemic and related policy responses of containment and social distancing. COVID 19 explicitly impacts organized treatment plans, interrupting schooling and recreation programs given by early childhood services, colleges and other groups. 188 nations have implemented nationwide school closures to date, affecting more than 1.5 billion children and young adults (UNSDG, 2020). 
COVID 19 exacerbates the risks of inadequate diet, mistreatment and vulnerability to abuse at home. It is important to understand that the consequences of these interventions can affect certain classes of kids more than others. Children living in poverty, children with disabilities, children in out-of-home care, children in custody, as well as immigrant children and children at risk of child labour are among these disadvantaged categories. In addition, the pandemic has the ability to produce new children who are vulnerable and countries need to plan to adapt to the increasing need for assistance. Depending on the level of abuse and source of reporting, reported rates of violence against women have both risen and decreased during COVID-19 in several nations. Calls to gender-based abuse centres were officially increasing in April in South Africa, while a group working closely with the National Prosecutor's Office, the police, and the Department of Social Development stated in May that incidents of rape and sexual harassment were down by $50 \%$. Such contradictory accounts are not unusual, but they pose several concerns regarding how multiple data sources can view and draw conclusions.

The COVID-19 scourge, which has spread to most parts of the world and has become a global epidemic, has not spared Kenya. The first case of COVID-19 in Kenya was registered in the Republic of Kenya (2020) in Nairobi (Kenya's capital) on 12 March 2020, resulting in many people fleeing to rural areas. Since then the state has placed in place some containment mechanisms to limit transmissions inside and around the county. However, since the first case was reported, the number of positive cases has been on a steady increase. The government tested 74,003 persons over a period of 3 months, with 1,745 positive tests as of 29 May 2020, and the largest single regular rise recorded was 147 cases (Republic of Kenya, 2020).

In periods of pandemics, people living in or near poverty often lack discretionary income and can not quickly store food. The compound susceptibility to the COVID-19 pandemic is stressed by obesity, starvation, pneumonia and other types of health-related shocks. While at least some channels are known that may potentially have beneficial consequences, we stress that the short-term difficulties faced by the crisis are serious especially for single mothers and other families with a lack of capacity to balance employment with caring for children at home. The situation and response of COVID-19 could expose communities to violations of human rights and more harm. There is a possibility that demonstrations, civil strife and violence will be caused by hard handed compliance and failure to respond to the basic needs of the people, especially food and water. Kenya face the effects of COVID-19, will be precarious and dangerous, with an increased likelihood of flooding and the spread of desert locusts.

\section{Literature Review}

\subsection{Economic Insecurity and Poverty-Related Stress}

While the full extent of economic impacts from COVID-19 is unclear, the US Treasury Secretary warned Congress in mid-March 2020 that if the government did not respond, unemployment rates could exceed levels of 20 percent. Pandemics will incite transient food insecurity and heightened tension even without immediate shocks to earning levels due to uncertainties regarding future economic stability or general well-being. Proof of the influence of COVID-19 is still very early and not yet well known, considering that the epidemic began in January 2020. Some of the early signs, however are that there are many places where it is possible that women and girls are at greater risk of abuse. In several nations, social distancing steps and stay-at-home directives placed since the COVID-19 crisis have had a significant effect on jobs, contributing to a dramatic increase in unemployment and shortened hours or temporary employment for other workers.

\subsection{Increased risk of domestic violence}

There is some evidence of a spike in domestic abuse in China, as well as questions in Italy and China regarding social programs. There is insufficient data from most countries, however, probably because steps of social distancing have just recently begun. Early data from China shows that in some areas of China, domestic abuse has escalated significantly and has tripled since the outbreak. Help services for survivors of domestic abuse, especially health care and police services, are increasingly overwhelmed by the effects of the epidemic. Police in China have been reported to be hesitant to interfere and arrest suspects due to COVID-19 outbreaks in jails (Wanqing, 2020). Some women's shelters have already been temporarily turned by the government into homeless shelters (Wanquing, 2020). UN Women have raised fears about the potential for diverting critical GBV health resources to resolve the epidemic (Owen, 2020). Examples of creative practices are however, still available to assist survivors, particularly through technical methods.

Women's groups in Italy have expressed questions about increased domestic abuse related to forced cohabitation of girls, husbands and older relatives, increased economic hardship and increased women's family workload in tandem with remote working conditions (di Redazione, 2020). DiRe, the nationwide domestic violence shelter network, has told Italians that their emergency telephone and Skype help are still available. Around 60 out of 80 local domestic violence agencies have mobile mobile lines that respond to calls (Ramundo, 2020). Italians also share the number of domestic violence groups on social media because they believe that the current health crisis and the ban on leaving the house would intensify domestic violence (Il Messagaro, 2020). 
There are rumors from several shelters that if they are infected, people are afraid of new women and children arriving at the site. In addition, as is the difficulty of keeping children busy, the social burden of being stuck inside the shelters with no hope of getting out is substantial. There are counselors in each of the centers who can offer assistance, but at a discreet distance and with masks and gloves (Ramundo, 2020).

\subsection{Increased risk of workplace violence in the health sector}

Due to the severe burden that COVID-19 puts on patients, their families and other healthcare staff, there are increasing fears that frontline healthcare workers are at heightened risk of abuse and assault. There are also cases of uniformed healthcare staff in public areas and on public transport suffering violence and bigotry. There is no study available on the gendered nature of epidemic-related abuse, but it should be remembered that $96 \%$ of nurses in China are female, and previous studies have found elevated levels of occupational violence against female nurses in hospitals in China, compounded by waiting times and medical insurance problems (Jiao et al, 2015).

In Singapore, during the COVID-19 outbreak, healthcare staff reported suffering bullying and violence, including when they were in uniform in public spaces and on public transport. Notices advise the people of polyclinics and hospitals that bullying of health care staff will not be accepted and will be forwarded to the authorities. There was a call to take serious action against those who threaten public space healthcare staff,' by using transport CCTV cameras to recognise and punish travelers who assault healthcare workers (Fernandez, 2020). In Iran, $24 \%$ of health staff have witnessed physical abuse in the past year with nurses being the primary victims $(78 \%)$ and patient relatives being the main offenders $(56 \%)$ in Iran (Fallahi-Khoshknab et al, 2016). No widely available proof of the effect of COVID-19 on Iranian healthcare workers has been identified in this report.

\subsection{Education and child protection responses}

Closing schools for the Ebola virus in West Africa subjected children to sexual abuse and violence (Christian Aid et al, 2015). In some affected areas, there was also a 'sharp spike' in teenage births and early marriages, leading to higher school dropout rates for girls (UNDP, 2015b and 2014). Outsiders who move goods into the neighborhood to offer facilities and who seek sex in exchange for help or take advantage of decreased caregiver oversight often have increased chances of sexual harassment and violence.

Owing to children being isolated from caregivers, being stigmatized, and difficulty receiving resources, outbreaks can cause and exacerbate child safety problems. In the DRC, after the Ebola outbreak, more than 4,000 children were isolated from their parents and there are over 2,000 Ebola orphans. Study in North Kivu showed that children living in areas affected by Ebola talked of terror, loneliness and stigma. The study showed that children are at risk of crime, neglect and exploitation unless their interests are focused on disease prevention and response (Hall, 2020).

\subsection{Quarantines and Social Isolation}

Quarantines can be extremely problematic for parenting, with established problems and violence magnified for children due to a confluence of school closures, fatigue, anxiety and confusion (Cluver et al., 2020). Quarantines also threaten increasing $\mathrm{VAW} / \mathrm{C}$ by increasing the day-to-day vulnerability of women and children to possible perpetrators. Latest research shows that rates of IPV decline due to exposure limitation as men move away from home.

Quarantine will intensify all offenders' current control habits as they try to recover a sense of control, including relational and other types of exclusion activities. Quarantine and other mechanisms of social distancing reduce physical autonomy and theoretically increase economic insecurity among women witnessing domestic abuse. There are pathways by which evolving social norms and standards are likely to intensify the COVID-19 pandemic. One is on the employer's side. Many organizations are now becoming much more aware of their workers' childcare requirements and react by introducing more flexible work hours and telecommuting opportunities quickly. Any of these improvements are likely to prove persistent by learning through doing and modifying norms. As a consequence, mothers and fathers alike will achieve versatility in certain places to fulfill the joint criteria of getting a job and running a household. Since currently women are more exposed to these competing demands, they stand to benefit disproportionately.

\subsection{Escape Abusive Partners}

Literature shows that the interest and willingness of women to leave violent relationships is nuanced, especially in LMICs, where divorce is rare and where family continuity is respected by social expectations and financial realities. Related support programs can also be impacted and trigger further delays, including emergency center screenings and crisis support services. A UNDP report analyzing the reaction to gender-based abuse during the Ebola outbreak reveals that failures in diagnostic tests contributed to the dismissal of court prosecutions due to a lack of adequate evidence (UNDP, 2015). 
The American Civil Liberties Union recommends in the current COVID-19 epidemic that parole officers should emphasize social distancing and connect by voice or video message, which could limit their ability to completely determine the risks of recurrence, particularly those that could put victims of IPV at increased risk (ACLU, 2020). These organisations could be less involved and willing to assist women and children in need, with social distancing policies introduced, as well as economic pressures. In periods of crisis, emergency assistance systems and new SMS-based security training and support initiatives are critical lifelines in their capacity to provide crisis management and strategic security planning even remotely.

The current COVID-19 epidemic may make it more difficult to enforce current preventive measures identified by women and girls, such as traveling in groups or ensuring that aid workers are accompanied while visiting refugee households. Given the possible scarcity of trained female workers due to containment initiatives, epidemic, or overlapping treatment demands in their own households, it will be extremely impossible to completely employ protected spaces and facilities for women and children (Fraser, 2020). In relief operations, getting women in response positions, such as nurses and aid workers, is seen as an important aspect of reducing SEA and can be important in the case of pandemics as well.

\subsection{Effect of COVID-19 on Workplace Flexibility and Gender Norms}

For the first time, more companies are now promoting work-from-home and telecommuting solutions on a large scale. Any of these modifications are expected to continue, leading to more stability in the workplace in the future. Given that mothers already bear a disproportionate responsibility of juggling employment and child care roles, these reforms are expected to gain comparatively more than men. As one of the final causes of the gender wage gap, Goldin (2010) points to a lack of consistency in job conditions and hours, particularly in financial and business services. Several parents will also now shoulder extra child care and home-schooling duties. Fathers would temporarily become sole child care providers in a sizeable number of households. In the provision of child care and housework, these shifts are expected to drive social standards for more inclusion.

During the recession, many fathers would work from home while still carrying on child care duties. It is possible that the very reality of being at home rather than at work raises the child care obligations of men. During the epidemic, this impact is expected to be great because, considering that schools and daycare facilities are closed, the overall demand for child care is much greater. The latest research on the impact of paternity leave (i.e. paternal leave reserved solely for dads) shows effects on comparatively minor changes; for instance, Farré and González (2019) offer proof that the implementation of paternity leave for fathers in Spain for only two weeks has persistent effects on the distribution of labor inside couples. Under the present recession, for a much longer period of time, several millions of men are on a sort of compulsory paternity leave, and a large fraction will be the primary providers of childcare during this time.

\section{Research Methodology}

The approach for this analysis consisted of a study of literature. Studies were found by Google searches and applicable electronic databases (Science Direct, and Google Scholar). Data was also found on social media. The data had to meet the following requirements to be considered for inclusion in this accelerated mapping: evidence on the effect of the COVID-19 pandemic on violence against women and girls. In all the cases published online, the publication available was used. Global geographical orientation, with focused searches as of mid-March 2020 in countries with the largest number of cases (China, Italy, Iran, South Korea) and in South Africa, Nigeria and Kenya regionally.

Owing to the very recent existence of the epidemic, evidence exists at an early stage about the effects of COVID-19. News stories and the websites of women's groups and others helping perpetrators of abuse offered the primary source of evidence. Restricted studies on the routes through which outbreaks may intensify multiple types of VAWG, and how within an outbreak separate factors of violence shift. Examples of good practice in delivering survivor assistance during COVID-19 are just beginning to appear from China, with few data from elsewhere available.

\section{Results}

A COVID-19 Taskforce was initiated by the Kenyan Ministry of Health (MOH) to lead prevention, containment and mitigation measures in the region. Containment is a significant first step to avoid the catastrophic health, social and economic effects of an epidemic of COVID-19. In addition, it would entail continued mitigation activities. The Government of Kenya suspended international flights entering and leaving Kenya on March 26 with the discovery of the first case of COVID-19 on March 13, 2020, and closed schools and banned major social gatherings Kabale (2020) barring these activities, including unique cultural and religious traditions such as mass prayer meetings, large weddings and funerals, are crucial to prevent super-spreading (Wong, Liu, Liu, Zhou, Bi \& Gao, 2015). Recently, under stringent precautions such as observing lengths, wearing goggles, using 
contact-free thermometers, eateries and restaurants, barber and salon shops have been re-opened and restaurants to observe specific protocols published by the Ministry of Health (Republic of Kenya, 2020).

\subsection{Impact of COVID-19 on Women and Girls}

When health service providers become overburdened with the treatment of COVID-19 incidents, life-saving care and assistance for GBV survivors, sometimes already constrained services, may be affected. For example, in February 2020, a non-governmental group helping GBV survivors in Jingzhou recorded three times more accounts of domestic abuse than in the same month last year (Sixth Tone, 2020). The COVID-19 pandemic would have a particularly negative impact on women and girls as opposed to men and boys in Kenya, with all these pathways strengthening each other.

In Kenya, COVID-19 can be predicted to affect women and girls overwhelmingly, while Wenham, Smith, and Morgan (2020) say that women tend to be less likely to die from the pandemic of COVID-19. Kenya's poor isolation ability in public and private health facilities and experience in countries where the pandemic is worse, makes it more likely that most infections will have to be treated at home, mainly by women, as infection rates increase. The propensity of women to be nurses for the sick will lead them to more infectious agents than men in both health-care contexts and at home.

Wenham, Smith, and Morgan (2020) highlight processes that affect women and children through pandemics:

School closures will raise the roles of women in childcare in reaction to pandemics, when women already share much of the responsibility for child-rearing, often affecting their livelihoods and job opportunities (Luiza Minardi, Hares and Lee Crawfurd, 2020).

Restrictions on travel would impact female international domestic workers. They impact male migrants, of course, too. Korkoya and Wreh (2015) found that 70 percent of Liberia's small-scale traders are women, so women were affected overwhelmingly by domestic travel restrictions during the Ebola outbreak. Women make up $70 \%$ of low wage earners in Kenya (Kenya National Bureau of Statistics, 2019). Many are working or operate micro and small businesses in the informal sector. This sector is distinguished by regular incomes, minimal measures for social security and savings, leaving women especially vulnerable during health pandemics.

\subsection{Impact of COVID-19 on Education}

As governments around the world have briefly closed schools in order to curb the spread of COVID-19, many women now have to tutor their children. More than 111 million girls who live in countries impacted by extreme poverty or war, where gender inequalities in education are largest, are deeply concerned about the effects of these school closures. Closures also driven over four million girls out of school in Mali, Niger, and South Sudan, three countries with some of the lowest enrolment and graduation rates for girls.

Meanwhile in Zambia, where the rate of girls dropping out from grade seven onwards is almost twice the rate of boys, before a single case of coronavirus was registered, the government agreed to shut all schools. The closing of schools would have a detrimental effect on schooling results for girls and boys alike in the mid to long term. But more worryingly, many girls will be reluctant to go back to school again, given the economic hardships created by COVID-19 and the heightened likelihood of underage pregnancy during lockdowns.

Like other countries impacted by COVID-19, Kenya briefly shut down schools and educational facilities to reduce the spread of the epidemic. School closures hinder instruction and compound disparities, influencing marginalized children overwhelmingly (Wang, Zhang \& Zhao 2020). School closures intensified dropouts, child labor, abuse against girls, adolescent pregnancy, and chronic socio-economic and gender inequalities throughout the 2014-16 Ebola outbreak. This had long-term implications on the educational, socioeconomic, and health outcomes of the children.

Epidemic-related quarantine steps and stress will build household stresses, leading to heightened parental anger and corporal punishment. School closures can raise the chances of multiple types of sexual harassment and violence, and early marriage for teenage girls. Outsiders who transport goods into the neighborhood to offer facilities and who seek sex in exchange for help or take advantage of decreased caregiver oversight also have increased chances of sexual harassment and violence. Owing to children being isolated from caregivers, being stigmatized, and difficulty receiving resources, outbreaks can cause and exacerbate child safety problems.

The COVID 19 pandemic is affecting children's health, social and material well-being globally, with the poorest children affected hardest, including homeless children and children in custody. The risk of inadequate nutrition in children, their vulnerability to domestic abuse, raising their anxiety and tension, and limiting access to critical family and care resources is exacerbated by school closures, social distancing and containment. Widespread digitalisation mitigates the lack of schooling triggered by school closing, but the poorer children are less likely to live with internet access in healthy home-learning environments. In addition, the increased unsupervised use of the internet online has increased concerns with sexual harassment and cyber-bullying.

For displaced or immigrant youngsters, temporary school closures may have acutely detrimental impacts for whom school can offer a supportive space for peer contact, psychosocial assistance, and even a stable source of 
food. If schools are closed, the loss of peer help and options for risk reduction could worsen the mental health challenges of children. There are grounds for concern that extended school closing and home detention during an outbreak of illness may have detrimental impacts on the physical and mental health of children (Brooks, Webster, Smith 2020).

\subsection{Impact of COVID-19 on Food Security and Nutrition}

Restrictions on transport and quarantine policies resulted in reduced food trade and accessibility, driving prices higher, while the population was less likely to participate in commercial activity. Some families are compelled to use adverse coping strategies to pay for food, such as limiting food intake, engaging in transactional sex, or borrowing cash or falling into debt. During public health crises, the possibility of elevated food poverty and malnutrition is especially serious for women and girls since in certain cases, societal expectations require that they consume last and least. Women and children, who are still more likely to be malnourished than males, increase their vulnerability to COVID-19 infection as food becomes scarce. Furthermore, quarantine measures and other movement restrictions can contribute to higher food insecurity, connecting economic insecurity and exploitative relationships to danger pathways.

\subsection{Effect of COVID-19 on Child Care Needs}

Another significant feature of the COVID-19 crisis is that it entails large-scale closing of daycare facilities and schools, which means that children remain at home, where they need to be cared for and taught (if possible). For single parents, this presents especially serious difficulties. The division of childcare for parents who raise their children together will rely on how much job versatility each parent has in terms of working from home and taking care of children as well. The new distribution of childcare within each family would possibly still rely on it.

The unexpected increase in childcare demands exacerbated by school and daycare closures is somewhat different from previous recessions. This will impact all households of children of school age or below. Mothers will be influenced very disproportionately by the present crisis. A number of alternative types of childcare plans are used in usual times. Many daycare facilities have however been ordered closed. Informal treatment carried out by mothers, other families, mates, or neighbours to delay the transmission of the infection is avoided or stopped by shelter-in-place orders. There is no room in the COVID-19 crisis for alternate arrangements.

\subsection{Childcare Responsibilities During the COVID-19 Crisis}

During the recession, many fathers would work from home while still carrying on child care duties. It is possible that the very reality of being at home rather than at work raises the child care obligations of men. During the epidemic, this impact is expected to be great because, considering that schools and daycare facilities are closed, the overall demand for child care is much greater. Therefore, even though as is likely) the bulk of the increase will be shouldered by ordinary mothers, many fathers will also see a significant increase in their child care hours. This higher awareness is likely to have at least some persistent impact on potential child care contributions, whether by understanding from doing so, more awareness on what children really do every day or through increased child attachment. Inside families where the COVID-19 crisis already results in a change in the proportional allocation of childcare hours towards males, we can expect much greater consequences.

Families where the mother is still living at home are one category for which this is likely to be the case, but the father formerly worked out of the house and is now either back at home or not employed. The greatest influence on the division of labor among families, where fathers briefly became the key provider of child care due to the COVID-19 crisis. For families where both spouses are still in the labour force, and where the father is able/forced to work from home during the crisis, assume this to be the case, whilst the mother is not.

\section{Conclusions}

Steps taken to deter the spread of COVID-19 are likely to result in loss of income and interruption of access to food, with an especially negative effect on people living in informal settlements. Market exits and business projects have also affected the rural population, making it impossible for agro-pastoral communities to obtain access to agricultural inputs, such as seeds and fertilizers, during a very crucial planting time during the long rainy season.

Closing schools for an extended time would affect the well-being of children and have a longer-term impact on inequality, as children especially teenage girls) will not be sent back to school by the most disadvantaged families. The closing of schools has impacted over 15.2 million pupils. Although distance learning mechanisms are being sought, both children and young people will not be met, and those lacking internet access or parental oversight will be disadvantaged. Children on the move are still impacted disproportionately by school delays and are at risk of being removed from internet or other opportunities for supplementary learning. School lunches and 
other community programs are no longer available for the poorer children when schools close, with possible implications on their nutritional status.

\section{Recommendation}

The overt and indirect gender consequences of the COVID-19 pandemic should be considered by the government and organisations, beyond basic binary statistics on the number of incidents. This is important to ensure that Kenya's response to the COVID-19 pandemic does not replicate or reinforce disparities in gender and health, gender norms, responsibilities and relationships that impact the unequal susceptibility of women and men to illness, exposure to pathogens and care received in order to be efficient.

To protect those who are the most impacted and most disadvantaged, build tailored economic development programs and social safety nets. Ensure that emergency preparedness and response strategies are focused on sound gender assessments, considering gender dynamics, threats, obligations, and social expectations, and considering the relevant capacities and needs of other vulnerable groups. This involves ensuring that prevention and response initiatives reflect the burdens of caregiving for women and girls and increased risks of GBV.

\section{References}

Altonji, Joseph G., Lisa B. Kahn, and Jamin D. Speer. 2016. "Cashier or Consultant? Entry Labor Market Conditions, Field of Study, and Career Success.” Journal of Labor Economics 34 (S1): S361-S401.

American Civil Liberties Union (2020). ACLU Follow Up Letter Urging COVID-19 Voting Legislation.https:/www.aclu.org/letter/aclu-follow-letter-urging-covid-19-voting-legislation-3222020

Brooks, S.K. Webster, R.K., Smith, L.E., Woodland, L., Wessely S., Greenberg, N., et al. (2020). The psychological impact of quarantine and how to reduce it: rapid review of the evidence. The Lancet 395: 912-20.

China Center for Disease Control. (2020). "Vital Surveillances: The Epidemiological Characteristics of an Outbreak of 2019 Novel Coronavirus Diseases (COVID-19)." China CDC Weekly 2:113-122.

Christian Aid, CAFOD, Tearfund, and Islamic Relief (2015) Keeping the Faith: The Role of Faith Leaders in the Ebola Response, London: Christian Aid. http:/learn. tearfund.org/ media/files/tilz/ research/keeping_the_faith_july_2015.pdf

Cluver, L., Lachman, J.M., Sherr, L., Wessels, I., Krug, E., Rakotomalala, S., et al. (2020). Parenting in a time of COVID-19. The Lancet (online first).

di Redazione (2020) 'Coronavirus, la denuncia di WeWorld: «Donne isolate, molte in compagnia dei maltrattanti»', Vita Internationale, 12 March 2020. http://www.vita.it/ it/article/ 2020/03/12/coronavirus-ladenuncia-di-weworld-donne-isolate-molte-in-compagnia-de/154412/

Fallahi-Khoshknab, M, Oskouie, F, Najafi, F, Ghazanfari, N, Tamizi, Z and Afghani, S (2016) 'Physical violence against health care workers: A nationwide study from Iran', Iran Journal of Nursing and Midwifery Research. 2016 May-Jun; 21(3): 232-238.

Farré, Lídia, and Libertad González. (2019). "Does Paternity Leave Reduce Fertility?" Journal of Public Economics 172:52-66.

Fernandez, P. (2020) 'Covid-19 outbreak: Take stern action against those who harass healthcare workers in public spaces', Today Online, https://www.todayonline.com/voices/take-stern-action-against-those-whoharass-healthcare-workers-public-spaces-during-covid-19

Fraser, E. (2020). Impact of COVID-19 Pandemic on Violence against Women and Girls. Helpdesk Research Report No. 284. London, UK: VAWG Helpdesk.

Goldin, Claudia. (2010). "How to achieve gender equality." The Milken Institute Review, pp. 24-33.

Hall, E (2020) Fear and Isolation: The impact of Ebola and war on child protection in the Democratic Republic of Congo, Uxbridge: World Vision.

Jarosch, Gregor. 2015. "Searching for Job Security and the Consequences of Job Loss." Unpublished Manuscript, Princeton University.

Jiao M, Ning N, Li Y, et al. (2015) 'Workplace violence against nurses in Chinese hospitals: a cross-sectional survey'. BMJ Open; 5: e006719.

Kabale N. (2020). Coronavirus: Kenya takes bold steps after cases rise to three. The Nation

Minardi, A. L., Hares, S., \& Crawfurd, L. (2020). Containing the Epidemic: Should Schools Close for Coronavirus?. Center for Global Development.

Messagaro (2020) 'Sui social i numeri da chiamare in caso di violenza domestica, gli effetti secondari del coronavirus', Il Messagaro, 12 March 2020

Owen, L (2020) 'Coronavirus: Five ways virus upheaval is hitting women in Asia', BBC World Service, 8 March 2020 https:/www.bbc.co.uk/news/world-asia-51705199 
Ramundo, L (2020) 'Coronavirus. Violenza donne, Veltri (D.i.Re): “Chiamateci, noi ci siamo”', DiRe, March 12 2020 https://www.dire.it/12-03-2020/432907-coronavirus-violenza-donne-veltri-d-i-re-chiamateci-noi-cisiamo/

Republic of Kenya (2020). Ministry of Health. First case of Coronavirus disease confirmed in Kenya. at $<$ https://www.health.go.ke/first-case-of-coronavirus-disease-confirmed-in-kenya/>

UNDP (2014) Assessing the Socio-Economic Impact of the Ebola Virus Disease in Guinea, Liberia and Sierra Leone: The Road to Recovery. New York: UNDP.

UNDP (2015a) Ebola Recovery in Sierra Leone Tackling the Rise In Sexual and Gender Based Violence And Teenage Pregnancy During The Ebola Crisis, New York: UNDP

UNDP (2015b) 'Confronting the gender impact of the Ebola Virus Disease on Guinea, Liberia and Sierra Leone', Africa Policy Note, Vol. 2, No. 1, 30 January 2015, p.4

UNESCO. (2020, April 17). COVID-19 Educational Disruption and Response. Retrieved April 17, 2020, from UNESCO: https://en.unesco.org/covid19/educationresponse

UNSDG . May; 2020. Policy Brief: COVID-19 and the Need for Action on Mental Health.https://unsdg.un.org/resources/policy-brief-covid-19-and-need-action-mental-health

Zhang, Y., Xiao, M., Zhang, S., Xia, P., Cao, W., Jiang, W., ... \& Wang, C. (2020). Coagulopathy and antiphospholipid antibodies in patients with Covid-19. New England Journal of Medicine, 382(17), e38.

Wanqing, Z. (2020). Domestic Violence Cases Surger During COVID-19 Epidemic. Accessed March 28, 2020: https://www.sixthtone.com/news/1005253/domestic-violence-cases-surge-during-covid-19-epidemic

Wenham, C., Smith, J., Morgan, R., (2020). "COVID-19: the gendered impacts of the outbreak" Available at https://www.thelancet.com/action/ showPdf?pii=S0140-6736\%2820\% 2930526-2

Wong G, Liu W, Liu Y, Zhou B, Bi Y, Gao G.(2015). MERS, SARS, and Ebola: The Role of Super-Spreaders in Infectious Disease. Cell Host \& Microbe;18(4):398-401. https://doi.org/10.1016/j.chom.2015.09.013. 